\title{
Glandular odontogenic cyst: A case report and immunohistochemical study
}

\author{
Takeshi Takayama, Katsuhiko Hayashi*, Hiroyuki Akiyama, Yuri Kirihara and Akihiro Ikai \\ Department of Dentistry, The Jikei University School of Medicine, Tokyo, Japan
}

\begin{abstract}
A glandular odontogenic cyst (GOC) is an uncommon jawbone cyst of odontogenic origin with characteristic histological findings of a lined epithelium that contains mucous cells, ciliated cells, and intraepithelial gland-like structures. We herein report a case of a GOC arising in the posterior region of the mandible in a 49-year-old man who was referred to our outpatient clinic for diagnosis of a radiolucent lesion of the right mandible. A panoramic radiograph and computed tomographic scan revealed a well-defined unilocular radiolucent area extending from the right second molar to the right mandibular ramus. The patient was treated by enucleation of the cystic lesion and open packing with gauze soaked in an antibiotic under general anesthesia. The surgical specimen was histologically examined and diagnosed as a GOC. No recurrence was found at the 3-year follow-up.
\end{abstract}

\section{Introduction}

Glandular odontogenic cysts (GOCs) are rare cystic lesions of odontogenic origin that were first described in 1988 by Gardner et al. [1]. The histologic features of GOCs are highly indicative of an odontogenic origin rather than a salivary gland origin. Therefore, in 1992, the World Health Organization established GOC as an independent histopathologic entity and listed the lesion as a developmental odontogenic epithelial cyst [2]. The characteristic histological findings of GOCs include a lined epithelium of varying thickness that contains mucous cells, ciliated cells, and intraepithelial gland-like structures. Some GOCs show clinically invasive growth, leading to a high rate of recurrence despite surgical excision. Previous reports pointed out cell kinetics and treatment modalities as factors responsible for the aggressive behavior of GOCs [3]. Examination for cytokeratin (CK) expression is reportedly useful for differentiation between GOCs and other lesions, including low-grade mucoepidermoid carcinoma and other odontogenic cysts [3]. We herein report a case involving immunohistochemical studies for CKs and Ki67 on the lined epithelium of a GOC.

\section{Case Report}

A 49-year-old man was referred to our outpatient clinic for diagnosis of a radiolucent lesion of the right mandible. At the first visit, intraoral examination showed no abnormality at the lesion site. A panoramic radiograph (Figure 1a) and computed tomographic (CT) scan (Figure 1b-d) revealed a well-defined unilocular radiolucent area extending from the distal aspect of the right second molar to the right mandibular ramus; the third molar was displaced toward the distal region and included in the lesion. Resorption of the second molar roots was evident. Inferior displacement of the mandibular canal was also seen, but neurosensory deficiency of the trigeminal nerve was not found. A contrast-enhanced CT scan revealed no significant enhancement in either the arterial or late phase. A biopsy was performed under a tentative diagnosis of odontogenic cyst or benign tumor. The histological diagnosis of the biopsy specimen was a GOC.
The patient was treated by extraction of the first, second, and third molars; enucleation of the cystic lesion; and open packing with gauze socked in an antibiotic under general anesthesia (Figure 2a, b). The resected mass was $25 \times 15 \times 15 \mathrm{~mm}$ in size and consisted of a thin cyst wall and unicystic space containing brown serous fluid. No recurrence was found at the 3-year of follow-up.

Histologic examination revealed a cystic lesion with luminal epithelium and surrounding connective tissue. The lining was composed of nonkeratinized stratified squamous epithelium of varying thickness lacking palisading of the basal cells. Eosinophilic columnar ciliated cells in the superficial layer formed irregular papillary projections, and mucous cells were present in the middle to superficial layer of the epithelium. Intraepithelial microcystic structures were occasionally seen. The underlying connective tissue consisted of dense fibrous tissue with chronic inflammation. The histological diagnosis of the surgical specimen was a GOC (Figure 3a, b).

Immunohistochemical staining for CK and MIB-1 was performed using the avidin-biotinylated enzyme complex method on formalinfixed, paraffin-embedded tissue. Immunohistochemical examination showed Ki67-positive cells scattered throughout the basal cell layer and a Ki67 labeling index of 1.4\% (Figure 3c). Strong CK8 immunoreactivity was detected in the surface layer, including in the ciliated and mucous cells (Figure 3d), while patchy, weak immunoreactivity for CK18 was detected in the surface layer (Figure 3e). CK19 staining was strong in all epithelial layers (Figure 3f).

*Correspondence to: Katsuhiko Hayashi, Department of Dentistry, The Jikei University School of Medicine, 3-25-8 Nishi-Shimbashi, Minato-ku, Tokyo 105 8461, Japan, Tel: +81-3-3433-1111; Fax: +81-3-5400-1293; E-mail: katsuh@jikei.ac.jp

Key words: glandular odontogenic cyst, immunohistochemistry, cytokeratin

Received: December 27, 2018; Accepted: December 29, 2018; Published: January 05, 2019 


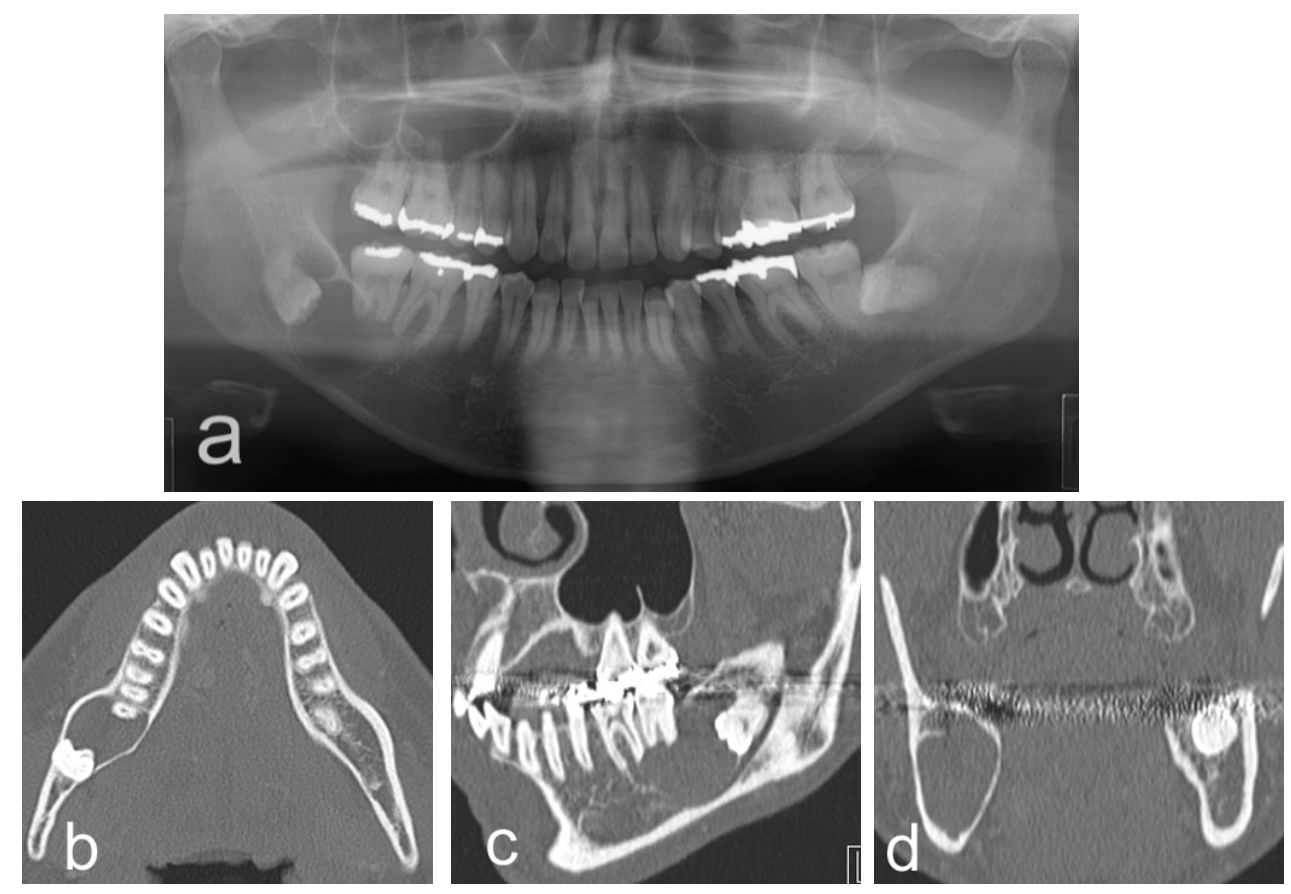

Figure 1. (a) Panoramic radiograph and (b) axial, (c) sagittal, and (d) coronal computed tomographic scans revealed a unilocular lesion in the right mandible.

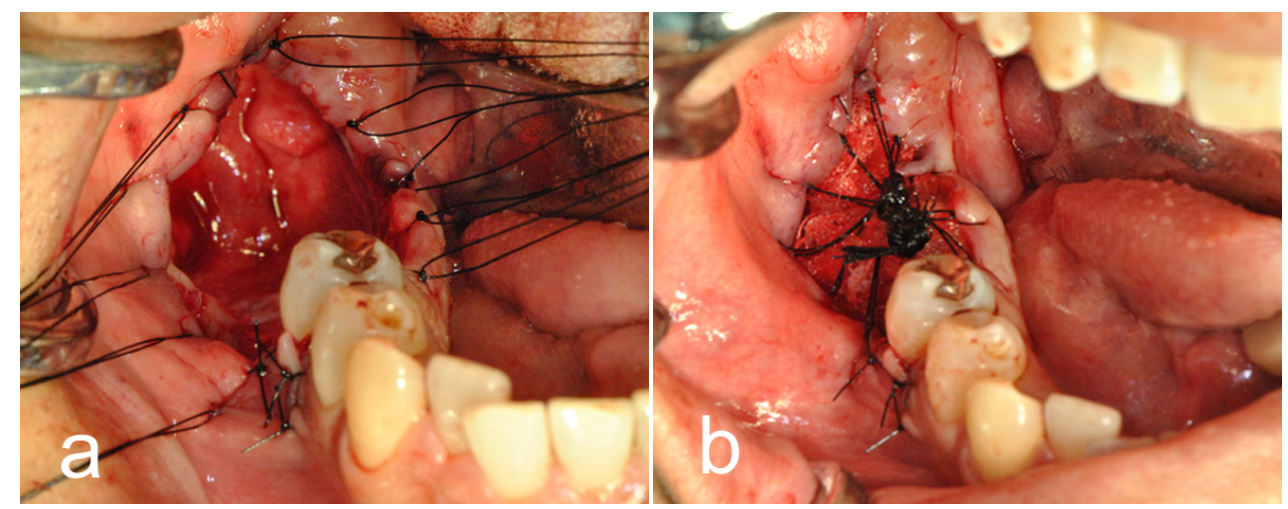

Figure 2. Intraoperative findings of (a) enucleation and (b) open packing with gauze.

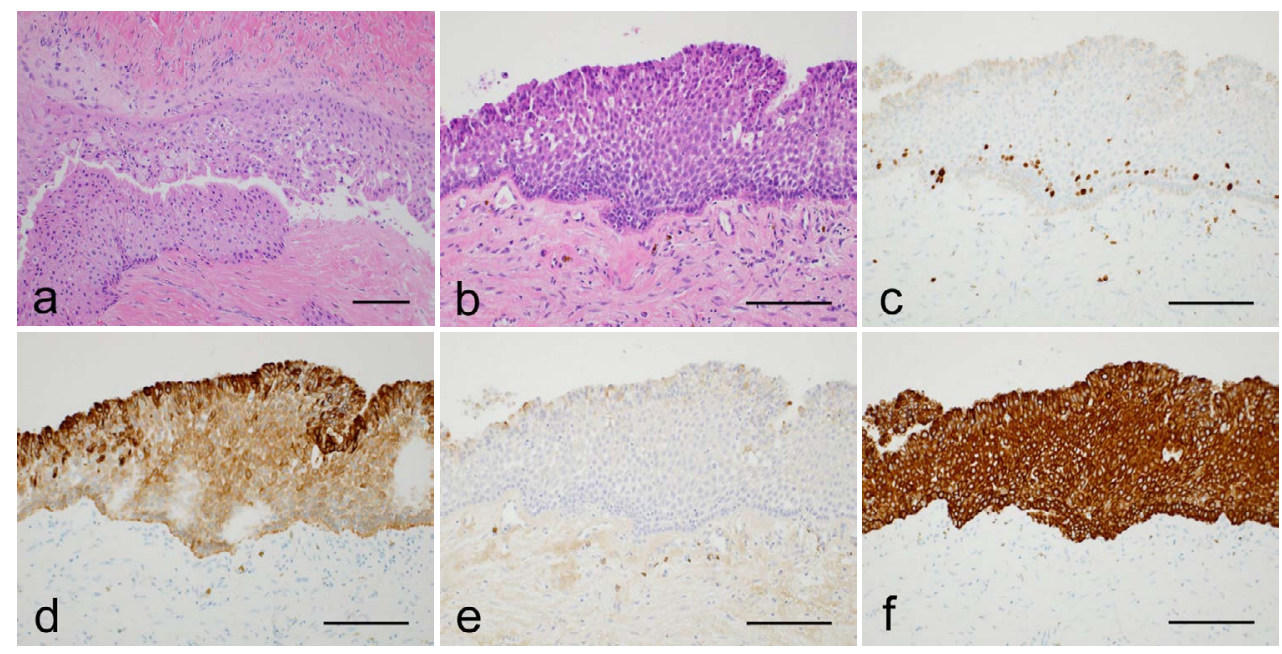

Figure 3. Histopathologic findings at (a) low-power magnification and (b) high-power magnification with hematoxylin and eosin staining. Columnar ciliated cells and mucous cells were present in the lining epithelium. (c) Scattered Ki67-positive cells were present among the basal and suprabasal cells. The surface layer contained cells that were (d) strongly positive for CK8 and (e) weakly positive for CK18. (f) All epithelial layers showed intense CK19 staining. Scale bar $=100 \mu \mathrm{m}$. 


\section{Discussion}

GOCs are rare cystic lesions with a frequency rate of $0.2 \%$ of jawbone cysts. Kaplan et al. [3] reviewed 111 cases of GOCs among 48 articles in the English-language literature and found that $57 \%$ of the GOCs occurred in males and $43 \%$ in females, with a wide age range of 14 to 75 years (mean, 45.7 years). Seventy percent of the GOCs were located in the mandible, and the onset rate in the posterior region was the same as that in the anterior region [3]. The GOC in the current case was found in the posterior region of the mandible in a 49-year-old man.

When diagnosing GOC, differentiation between low-grade central mucoepidermoid carcinoma and GOC is crucial because of their morphological similarity. The characteristics of CK expression are significantly different between GOC and low-grade central mucoepidermoid carcinoma [3,4]. In the current case, immunoreactivity for CK19, which is expressed in the odontogenic epithelium, was strong in all epithelial layers, and immunoreactivity for CK18, which is expressed in the glandular system, was quite weak and only present in the surface layer. Immunohistochemical staining for CKs can be used as an aid to distinguish between GOC and low-grade central mucoepidermoid carcinoma. Furthermore, the CK expression in the current case was not specific to GOC and was similar to that of other odontogenic cysts and epithelium in previous reports $[5,6]$. These findings might indicate that GOCs originate from the odontogenic epithelium.

GOCs have an aggressive potential and high rate of recurrence. The recurrence rate after treatment of GOCs is approximately $30 \%$ in published cases that include follow-up information [3]. Cell kinetics and treatment modalities have been reported as factors responsible for the tendency of GOCs to recur. In the present case, the cell proliferative ability as evaluated by Ki67 immunostaining was low, and the result was in agreement with the findings reported by Tosios et al. [7]; the high recurrence rate of GOCs was considered to be associated with incomplete removal of the lesion, not with cell proliferation. In the present case, enucleation of the cystic lesion and open packing with gauze were performed to allow for observation of recurrence in the enucleation fossa. Careful long-term clinical and radiological followup are important because of the high recurrence rate of GOCs.

\section{Competing Interests}

The authors declare that they have no competing interests.

\section{References}

1. Gardner DG, Kessler HP, Morency R, Schaner DL (1988) The glandular odontogenic cyst: an apparent entity. J Oral Pathol 17: 359-66. [Crossref]

2. Kramer IR, Pindborg JJ, Shear M (1992) The WHO Histological typing of odontogenic tumors. A commentary on the Second Edition. Cancer 70: 2988-94. [Crossref]

3. Kaplan I, Anavi Y, Hirshberg A (2008) Glandular odontogenic cyst: a challenge in diagnosis and treatment. Oral Disease 14: 575-81. [Crossref]

4. Pires FR, Chen SY, da Cruz Perez DE, de Almeida OP, Kowalski LP (2004) Cytokeratin expression in central mucoepidermoid carcinoma and glandular odontogenic cyst. Oral Oncol 40: 545-51. [Crossref]

5. Gao Z, Mackenzle IC, Cruchley AT, Williams DM, Leigh I, et al. (1989) Cytokeratin expression of the odontogenic epithelia in dental follicles and developmental cysts. $J$ Oral Pathol 18: 63-7. [Crossref]

6. Shen J, Fan M, Chen X, Wang S, Wang L, et al. (2006) Glandular odontogenic cysts in China: report of 12 cases and immunohistochemical study. J Oral Pathol Med 35: 175-82. [Crossref]

7. Tosios KI, Kakarantza-Angelopoulou E, Kapranos N (2000) Immunohistochemical study of bcl-2 protein, ki-67 antigen and p53 protein in epithelium of glandular odontogenic cysts and dentigerous cysts. J Oral Pathol Med 29: 139-44. [Crossref]

Copyright: (2019 Takayama T. This is an open-access article distributed under the terms of the Creative Commons Attribution License, which permits unrestricted use, distribution, and reproduction in any medium, provided the original author and source are credited. 